\title{
EVALUATION OF CORROSION RESISTANCE OF IMPLANT-USE Ti6AI4V ALLOY IN HANK BIOLOGICAL SOLUTION IN THE PRESENCE OF MICROORGANISM'S METABOLIC PRODUCT LACTIC ACID
}

\author{
Lidia BENEA*, Nicoleta SIMIONESCU \\ Research (Competences) Centre: Interfaces-Tribocorrosion-Electrochemical Systems (CC-ITES), Dunarea de \\ Jos University of Galati, 47 Domneasca Street, 800008 Galati, Romania \\ e-mail: Lidia.Benea@ugal.ro; Tel.: +40-744-216277
}

\begin{abstract}
Titanium alloys such as $\mathrm{Ti}_{6} \mathrm{Al}_{4} V$ is the most used alloy used as implant for biomedical purposes. The conditions for a biomaterial to be selected for a particular application in the human body is that this should to conforms to the physical, chemical and biological characteristics, more precisely to be biocompatible, biofunctional and not ultimately sterilizable. $\mathrm{Ti}_{6} \mathrm{Al}_{4} \mathrm{~V}$ alloy has mechanical properties suitable for many biomedical applications and has excellent corrosion resistance, which depends on the presence of a stable passive oxide film forming on its surface. Our study aims to evaluate the corrosion resistance of Ti6Al4V as a function in time with addition of $5 \mathrm{~g} / \mathrm{L}$ and $10 \mathrm{~g} / \mathrm{L} \mathrm{Lactic}$ acid in biological solution Hank after exposure at $0 \mathrm{~h}$ (at immersion time), after $48 \mathrm{~h}$ (from immersion) and $168 \mathrm{~h}$ (from immersion). The evaluation of corrosion resistance of Ti6Al4V in Hank biological solution with addition of two concentration of Lactic acid it was done by electrochemical methods in terms of open circuit potential and polarization resistance (Rp). Lactic acid is used in this study because it is a component present in human blood in small quantities and is necessary for the metabolic processes used directly by the heart muscle, brain and nervous system. The increased lactic acid content in muscle appears as weight-bearing exercises.

This is why it is important to know how the presence of lactic acid in larger quantities affects the implants. The study also highlights the importance of using longer testing times and more realistic solutions when testing biomedical materials.
\end{abstract}

KEYWORDS: Electrochemical corrosion; Titanium alloys Ti6Al4V; Lactic acid; Biological solution Hank

\section{Introduction}

The technological advances that have transformed our world over the last 20 years have been based on developments in Materials Science and Engineering. Materials are evolving today faster than ever in history, allowing engineers to improve the performance of existing products and to develop innovative technologies that will improve every aspect of our lives [1].

The field of biomaterials is essential for the development of surgery, allowing the extension of treatment options, more effective treatments and creating opportunities for less invasive treatment. The selection of the material must be correlated with the chemical and mechanical properties, while maintaining the biocompatibility and safety [1].

The corrosion resistance of the materials is an essential condition for the metals to be introduced into the human body, because the biocompatibility [14] of the metal-tissue must be guaranteed so as to avoid any deterioration of the tissue. Biocompatibility is described as the ability of a biomaterial to perform its desired function in relation to medical therapy, without causing undesirable local or systemic effects to the recipient [1-4]. Implantable medical devices are increasingly important in the practice of modern medicine. Unfortunately, almost all medical devices are affected to a different extent by adverse reactions, including inflammation, fibrosis, thrombosis, and infection. In order to improve the safety and function 
of many types of medical implants, there is a major need for the development of materials with physical chemical characteristics of the desired surfaces. Because associated with the implant surface are protein adsorption and conformational changes, which promote immune reactions, rigorous research efforts have been highlighted in the engineering of surfaces of biomaterials (physical and chemical characteristics), surface properties to reduce protein uptake and interactions and subsequently to improve implant biocompatibility $[1,5]$.

Therefore, the biocompatibility of implants can be regarded as a surface phenomenon of biomaterials and response of biological fluids and human tissues to their interaction and to the reactivity of the material / biological interface [1].

The corrosion of the implants is the deterioration suffered as a result of interactions with the biological environment (electrochemical attack), which causes the release of ions into the environment. It is important to note that no metal or alloy is completely inert in vivo. And the phenomena of corrosion at the interface biomaterial - implant and the biological environment are particularly important in the evolution of dental and orthopaedic implants and can cause implant failures after an initial success. Degradation of a metal implant is undesirable because it negatively alters the structural integrity of the implant [1, 6-10].

Corrosion is one of the most important processes that cause problems for metals and alloys that are used as implants in the body [1-2]. In order to minimize these problems, a better understanding of some of the basic principles involved in the corrosion degradation process of biomaterials is needed. The corrosion of implants in the aqueous environment of body fluids occurs through electrochemical reactions [1-2], and it is necessary to appreciate and understand the electrochemical principles that are most relevant for corrosion processes. The electrochemical reactions that take place on the surface of the surgically implanted alloys are identical to those observed during exposure to solutions that simulate biological fluids in the human body (blood, saliva, etc.).

The electrochemical methods evaluate the properties of the materials in real time in their operation in the environment of use. As an example, are the electrochemical methods of assessing the corrosion resistance of materials and biomaterials in specific environments of use. Electrochemical methods are widely used to characterize materials or biomaterials both from the point of view of their resistance in specific environments of use, biocompatibility or electrocatalytic effects for the efficiency of different synthesis reactions.
Electrochemistry has certain advantages over conventional methods, because it allows the direct generation and identification, in a fast and clean manner, of both stable species and metabolites, with short half-lives, without the need to use laboratory animals or organ extracts. In addition, it can be a powerful tool in interaction studies with specific cellular components, which is more difficult to achieve by in vivo or in vitro methods.

It should also be mentioned that, in general, complete results regarding a certain corrosion process are obtained by using several complementary methods in parallel [2]. Methods for investigating corrosion and kinetics of electrode processes can be electrochemical and non-electrochemical [2, 11-12]. The first category includes the methods in which the disturbance of the studied system and the monitoring of the response given by the system to this disturbance are made with an electrical signal (current, potential, quantity of electricity, etc.) [1-2]. In the second category are methods that use other sizes than electrical ones and which can be used to obtain information complementary to those provided by electrochemical methods (spectroscopic, optical, electron microscopy, X-ray diffraction, etc.) [1-2]. Electrochemical methods are considered to be the most effective for in situ investigations, these being also the most accessible and most commonly used methods for characterizing and evaluating the corrosion resistance and kinetics of an electrode process. The electrochemical methods used can be classified according to several criteria [1-2]. Depending on the speed with which the studied system is disturbed they can be: steady state and nonsteady state (relaxation). In the steady state methods, the disturbance of the system takes place at such a low speed that it can be considered in equilibrium, whereas in the non-steady state methods, the disturbance occurs rapidly, following the system's response during its return to a new one steady state.

Lactic acid is a colourless substance produced by almost all tissues of the human body to ensure its proper functioning. Lactic acid is used in this study because circulates in the blood system at any time in small quantities. It is produced by the tissues of the body, mainly the muscles, to obtain energy by metabolizing glucose in the absence of oxygen. Glucose can be used either from the bloodstream or from the form stored by the body, glycogen in the muscles. This process is called anaerobic respiration (without oxygen). Lactic acid (in large quantities) is produced during weight-bearing exercises, and if the amount of it in the muscle is very high, fatigue and muscle cramps occur [13-15].

Our work aims to investigate the effect of Lactic Acid as metabolic product of microorganisms on the corrosion behaviour of Ti6Al4V in Hank biological 
solution. The results show that Lactic Acid could improve the degradation process of titanium alloy immersed in Hank biological solution.

\section{Materials and methods}

Before any experiment for the evaluation of a material, an experimental protocol should be established, comprising all the measurements and the steps necessary for the accuracy of the experiments and the results obtained [1-2]. In general, for the evaluation of the corrosion resistance of the materials and of the corrosion kinetics and mechanism, an experimental protocol may include the following steps [2]:
- The selection of a suitable electrochemical cell so that it is schematized in Figure 1 (with three electrodes). The electrolyte volume must be constant for each measurement [2].

- Choosing and preparing the samples from the tested alloy, respectively $\mathrm{Ti6} \mathrm{Al} 4 \mathrm{~V}$ with a surface roughness and chemical composition as it was received from customer $(\mathrm{Ra}=1.15 \mu \mathrm{m})$ presented in another article [4].

- Correct preparation of test solutions. In the experiment it was used Hank biological solution simulating the blood from the body and addition of two concentrations of lactic acid which is known as one of metabolic product of microorganisms.

The chemical composition of biological fluid used for this study is presented in Table 1 .

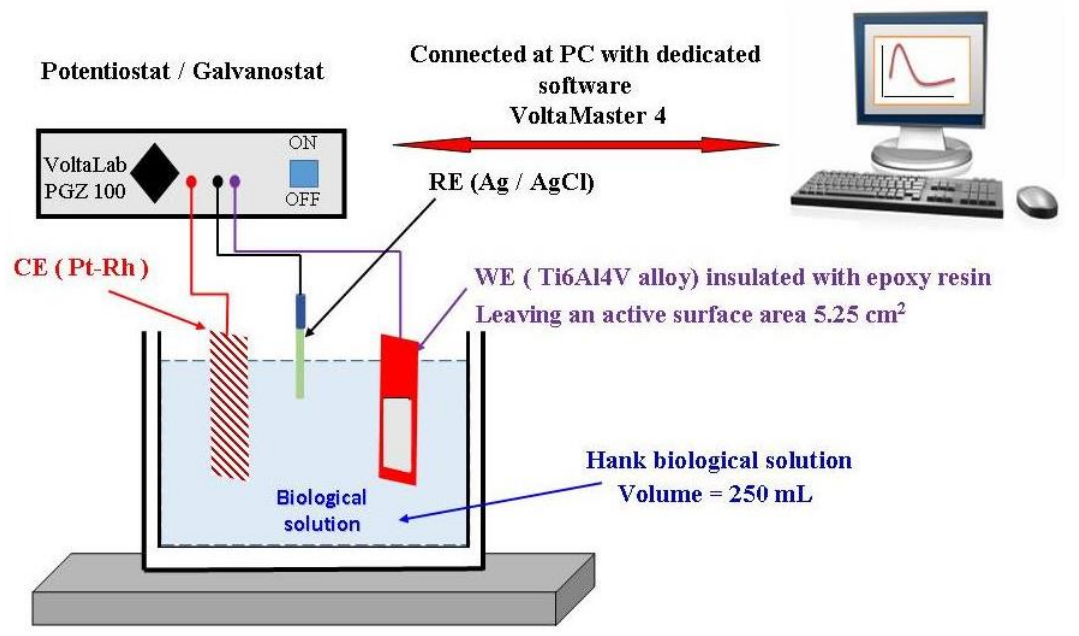

Fig. 1. Schematic representation of electrochemical cell used for corrosion investigation

Table 1. Composition of Hank biological solution without and with Lactic Acid addition

\begin{tabular}{|c|c|c|c|}
\hline $\begin{array}{l}\text { Compound } \\
{[\text { g / L ] }}\end{array}$ & $\begin{array}{c}\text { Hank } \\
\text { solution }\end{array}$ & $\begin{array}{c}\text { Hank } \\
\text { +Lactic Acid } \\
5 \mathrm{~g} / \mathrm{L}\end{array}$ & $\begin{array}{c}\text { Hank } \\
\text { +Lactic Acid } \\
10 \mathrm{~g} / \mathrm{L}\end{array}$ \\
\hline $\mathrm{NaCl}$ & 8.8 & 8.8 & 8.8 \\
\hline $\mathrm{KCl}$ & 0.4 & 0.4 & 0.4 \\
\hline $\mathrm{CaCl}_{2}$ & 0.14 & 0.14 & 0.14 \\
\hline $\mathrm{NaHCO}_{3}$ & 0.35 & 0.35 & 0.35 \\
\hline $\mathrm{Na}_{2} \mathrm{HPO}_{4} \cdot 7 \mathrm{H}_{2} \mathrm{O}$ & 0.06 & 0.06 & 0.06 \\
\hline Lactic Acid & - & 5 & 10 \\
\hline $\mathrm{C}_{6} \mathrm{H}_{12} \mathrm{O}_{6}$ & 1 & 1 & 1 \\
\hline $\mathrm{MgSO}_{4} \cdot 7 \mathrm{H}_{2} \mathrm{O}$ & 0.2 & 0.2 & 0.2 \\
\hline $\mathrm{KH}_{2} \mathrm{PO}_{4} \cdot \mathrm{H}_{2} \mathrm{O}$ & 0.1 & 0.1 & 0.1 \\
\hline $\mathrm{pH}$ & 7.4 & 2,67 & 1.98 \\
\hline $\begin{array}{c}\text { Conductivity, } \\
{[\mathrm{mS} / \mathrm{cm}]}\end{array}$ & 14.6 & 14.7 & 15.6 \\
\hline
\end{tabular}

- Establishing an experimental protocol that includes both the preparation of the samples before immersion in the test solution and the electrochemical measurements imposed on an electrochemical 
workstation. The diagram of the protocol with the programming of the electrochemical measurements for each type of solution used is presented in Figure 2.

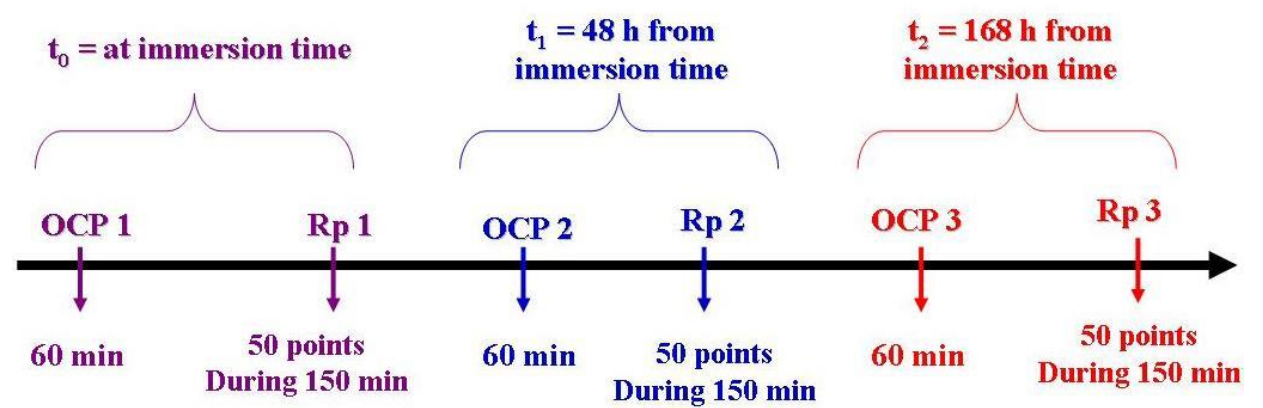

Fig. 2. Schematic representation of experimental protocol used for electrochemical measurements

The two methods used, namely open circuit potential (OCP) and polarization resistance (Rp) emitted from 50 linear polarization (LP) measurements for each sample immersed in each solution, will give some information about the trend of potential evolution of titanium alloy in the tested biological solutions. Measuring the free potential from immersion in the solution according to the set time. The potential of an electrode is measured by reference to a reference electrode [2]. The potential of the reference electrode, $\mathrm{E}_{\text {ref }}$, is reproducible and stable over time. The potential of the reference electrode is independent of the solution in which it is used and is the same regardless of the type and experimental conditions that are carried out. For this experiment, the reference electrode $\mathrm{Ag} / \mathrm{AgCl}(\mathrm{E}=199 \mathrm{mV}$ vs. the normal hydrogen electrode) was used.

The polarization resistance, $R_{p}$, is an important parameter to evaluate the passivation capacity of a biomaterial or to study a uniform corrosion process that occurs on a metallic surface. Each experimental point (polarization resistance and potential versus time) is automatically recorded and obtained from an individual voltammogram, or individual linear polarization, which is automatically, processed using an algorithm introduced in the pilot program and recording of experimental data. These individual voltammograms are saved. This makes it possible to process them with the second Stern method. Between two successive voltammograms the system returns to the free potential.

The polarization resistance was determined by plotting the linear voltammetry curves around the free potential with a small $\pm 40 \mathrm{mV}$ disturbance and a low scan rate of $1 \mathrm{mV} / \mathrm{sec}$. Fifty (50) such measurements have been programmed to show us an evolution of the polarization resistance over time in the respective corrosive environment.

\section{Results and discussion 3.1. Open circuit potential (OCP)}

The interface between an electronic conductor and an electrolyte acts as an electrode. As a result of the transfer of charges between the two phases in contact, between the electronic conductor and the electrolyte solution a potential difference is called electrode potential [2].

The variation in potential of the open circuit potential follows the behaviour of a biomaterial in contact with a corrosive liquid environment. After a period of immersion, it stabilizes around a stationary value [2], called free potential or open circuit potential at that time. Corrosion tests should always be initiated with the monitoring of the free potential starting from the immersion of the samples in the respective corrosive test environments [2]. The plot of the E(t) curves for the Ti6Al4V alloy immersed in the three solutions is shown in Figures 3-5, for immersion time 0 , after 48 hours and after 168 hours from immersion.

From Figure 3, after immersion it is observed that the open circuit potential of titanium alloy immersed in Hank solution becomes stable at a value of $160 \mathrm{mV}$ vs. $\mathrm{Ag} / \mathrm{AgCl}$, while the open circuit potential of titanium alloy immersed in Hank solution with $5 \mathrm{~g} / \mathrm{L}$ Lactic acid is stabilized at a more positive (noble) value of $430 \mathrm{mV}$ vs. $\mathrm{Ag} / \mathrm{AgCl}$ having a low decreasing tendency to less noble values. The open circuit potential of titanium alloy immersed in Hank solution with $10 \mathrm{~g} / \mathrm{L}$ Lactic Acid is stabilized at about $230 \mathrm{mV}$ vs. $\mathrm{Ag} / \mathrm{AgCl}$, which is less noble than that of $5 \mathrm{~g} / \mathrm{L}$ Lactic Acid and a little much positive as compared with Hank solution. It can be concluded that in the very first contact of Lactic acid with titanium alloy surface immersed in Hank solution the effect is to improve the passive capacity and to shift their open circuit potential to more positive (noble) values. 


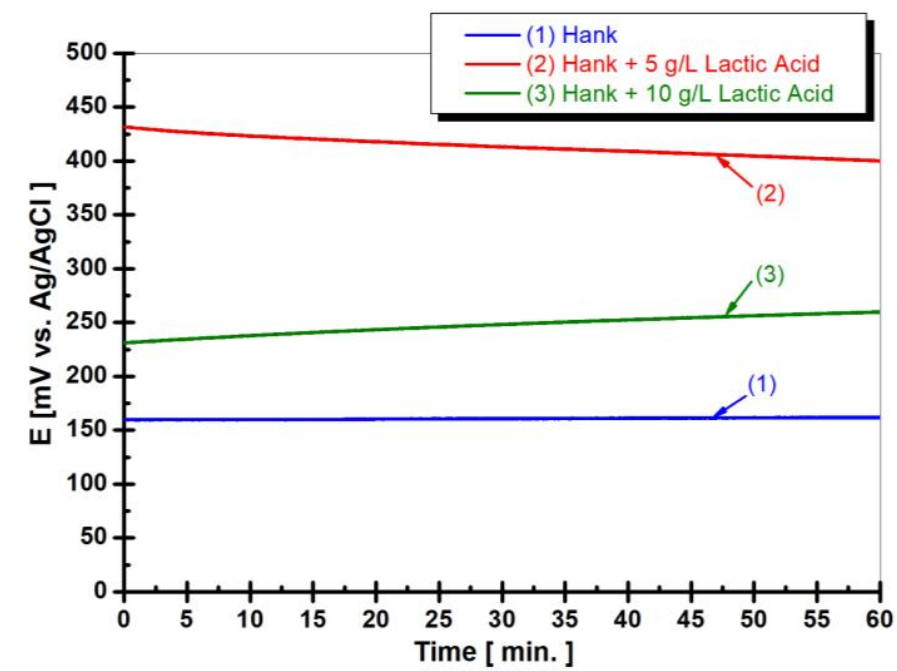

Fig. 3. Open circuit potential of titanium alloy after immersion in: (1) Hank solution; (2) Hank with 5 g/L Lactic Acid added; (3) Hank with $10 \mathrm{~g} / \mathrm{L}$ Lactic acid added

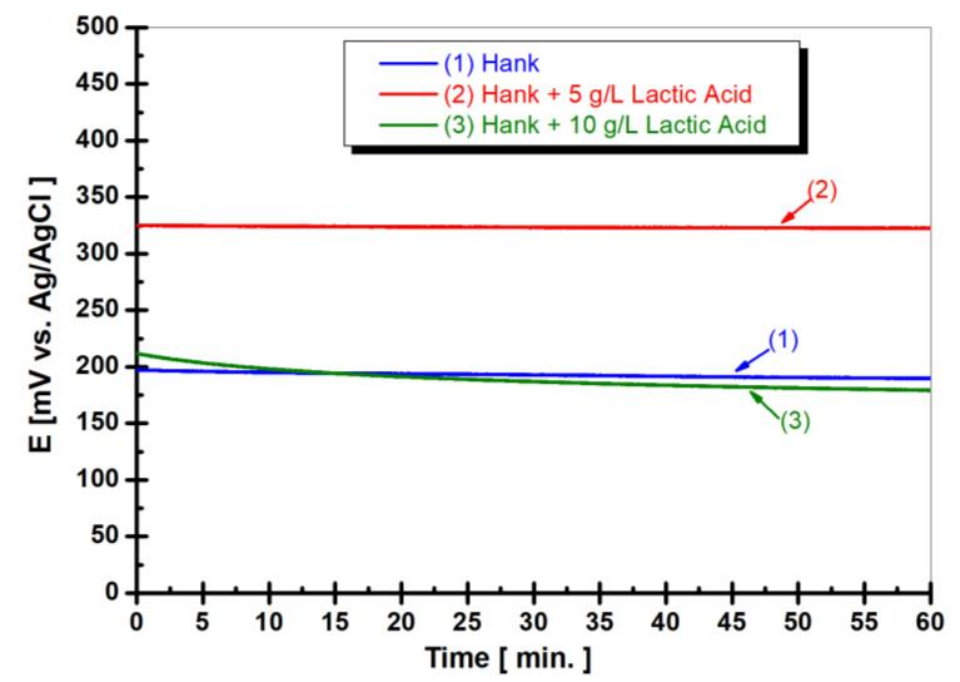

Fig. 4. Open circuit potential of titanium alloy measured after $48 \mathrm{~h}$ from immersion in: (1) Hank solution; (2) Hank with $5 \mathrm{~g} / \mathrm{L}$ Lactic Acid added; (3) Hank with $10 \mathrm{~g} / \mathrm{L}$ Lactic acid added

After $48 \mathrm{~h}$ from immersion time, Figure 4, the open circuit potential of titanium alloy immersed in Hank solution is slowly decreasing to less positive values at $198 \mathrm{mV}$ vs. $\mathrm{Ag} / \mathrm{AgCl}$, while the open circuit potential of titanium alloy immersed in Hank with 5 $\mathrm{g} / \mathrm{L}$ Lactic Acid solution is also decreasing to less noble values but much nobler than Hank solution, respectively at $326 \mathrm{mV}$ vs. $\mathrm{Ag} / \mathrm{AgCl}$. The open circuit potential of titanium alloy immersed in Hank solution with $10 \mathrm{~g} / \mathrm{L}$ Lactic Acid is stabilized at about the same value as Hank solution of $210 \mathrm{mV}$ vs. $\mathrm{Ag} / \mathrm{AgCl}$ but with a low decreasing tendency to fewer noble values.

After $168 \mathrm{~h}$ from immersion time, the open circuit potential showed in Figure 5, of titanium alloy immersed in Hank solution is decreasing to fewer positive values having a constant value of $160 \mathrm{mV}$ vs. $\mathrm{Ag} / \mathrm{AgCl}$ as the first time of immersion in this solution. The open circuit potential of titanium alloy immersed in Hank solution with $5 \mathrm{~g} / \mathrm{L}$ Lactic Acid is stabilized at a much less positive (noble) value of 290 $\mathrm{mV}$ vs. $\mathrm{Ag} / \mathrm{AgCl}$ having a decreasing tendency.

The open circuit potential of titanium alloy immersed in Hank solution with $10 \mathrm{~g} / \mathrm{L}$ Lactic Acid is stabilized at about the same value as Hank solution of $160 \mathrm{mV}$ vs. $\mathrm{Ag} / \mathrm{AgCl}$ but with a low decreasing tendency to fewer noble values. It can be concluded that the effect of Lactic Acid is changing during immersion time and therefore will contribute to progression of corrosion process on titanium alloy surface immersed in Hank solution. 


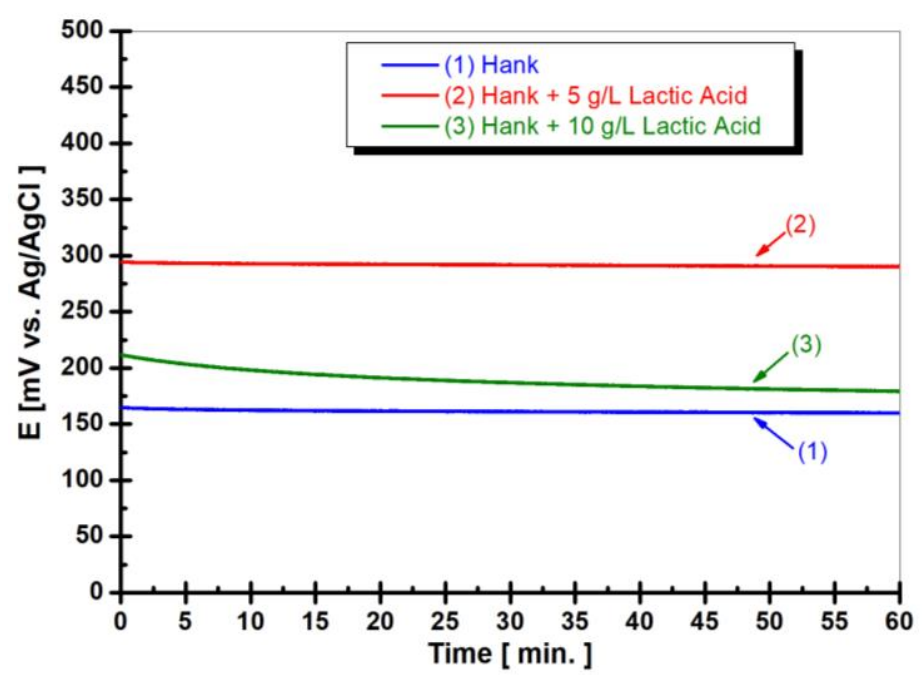

Fig. 5. Open circuit potential of titanium alloy measured after $168 \mathrm{~h}$ from immersion in: (1) Hank solution; (2) Hank with $5 \mathrm{~g} / \mathrm{L}$ Lactic Acid added; (3) Hank with $10 \mathrm{~g} / \mathrm{L}$ Lactic acid added

\subsection{Polarization resistance, $R p$}

The evolution of polarization resistance resulted from 50 measured voltammograms around free potential for each solution is presented in Figures 6-8 for every period of immersion, respectively: immersion time $(\mathrm{t}=0 \mathrm{~h}), 48 \mathrm{~h}$ and $168 \mathrm{~h}$.

The polarization resistance $(\mathrm{Rp})$ is determined using the Stern Geary formula, as it is explained in many specialized books $[2,16]$ :

$$
R_{p}=\frac{\Delta E}{\Delta i}=\frac{\beta_{a} \cdot \beta_{c}}{2,3 \cdot\left(\beta_{a}-\beta_{c}\right) \cdot i_{c o r}}
$$

where: $-\beta_{a}$ şi $\beta_{c}$ are Tafel anodic and cathodic slopes, $(\Delta \mathrm{E} / \Delta \mathrm{i})$ tangent to polarization curve in corrosion potential.

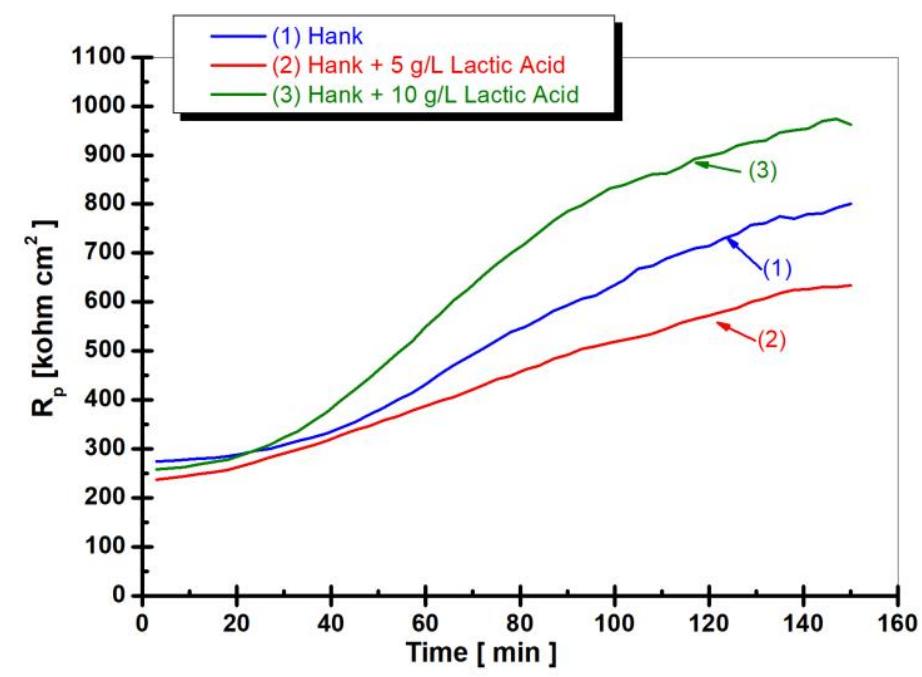

Fig. 6. Evolution of polarization resistance of titanium alloy after immersion in: (1) Hank solution; (2) Hank with $5 \mathrm{~g} / \mathrm{L}$ Lactic Acid added; (3) Hank with $10 \mathrm{~g} / \mathrm{L}$ Lactic acid added

As it could be seen from Figure 6 the polarization resistance of titanium alloy immersed in the three types of solution starts at about same values at very immersion time. During measuring period, the polarization resistance of titanium alloy immersed in
Hank solution is shifting to higher values from 275 $\mathrm{kohm} \cdot \mathrm{cm}^{2}$ to $710 \mathrm{kohm} \cdot \mathrm{cm}^{2}$ showing that the Ti6Al4V alloy in Hank solution forms an oxide passive film which improves the corrosion resistance of the alloy in biological solution. The addition of low 
concentration of Lactic Acid of $5 \mathrm{~g} / \mathrm{L}$ follow the same trend for polarization resistance of titanium alloy as in Hank solution but with slow lower values, from $220 \mathrm{kohm} \cdot \mathrm{cm}^{2}$ to $610 \mathrm{kohm} \cdot \mathrm{cm}^{2}$. This behaviour could suggest that at this concentration the lowering of polarization resistance decreases also the corrosion resistance of titanium alloy immersed in Hank solution with $5 \mathrm{~g} / \mathrm{L}$ Lactic Acid. Adding a higher concentration of Lactic Acid in Hank solution, respectively $10 \mathrm{~g} / \mathrm{L}$ can be observed that titanium alloy immersed in this solution have a higher value of polarization resistance. This behaviour suggests the effect of passivation of Lactic Acid when is present in biological solution. This higher passivity effect could sensitize the titanium alloy surface on localized corrosion. The polarization resistance of titanium alloy immersed in Hank solution with $10 \mathrm{~g} / \mathrm{L}$ Lactic Acid increases during immersion period, after $48 \mathrm{~h}$, from $230 \mathrm{kohm} \cdot \mathrm{cm}^{2}$ to $900 \mathrm{kohm} \cdot \mathrm{cm}^{2}$, registering the highest values.

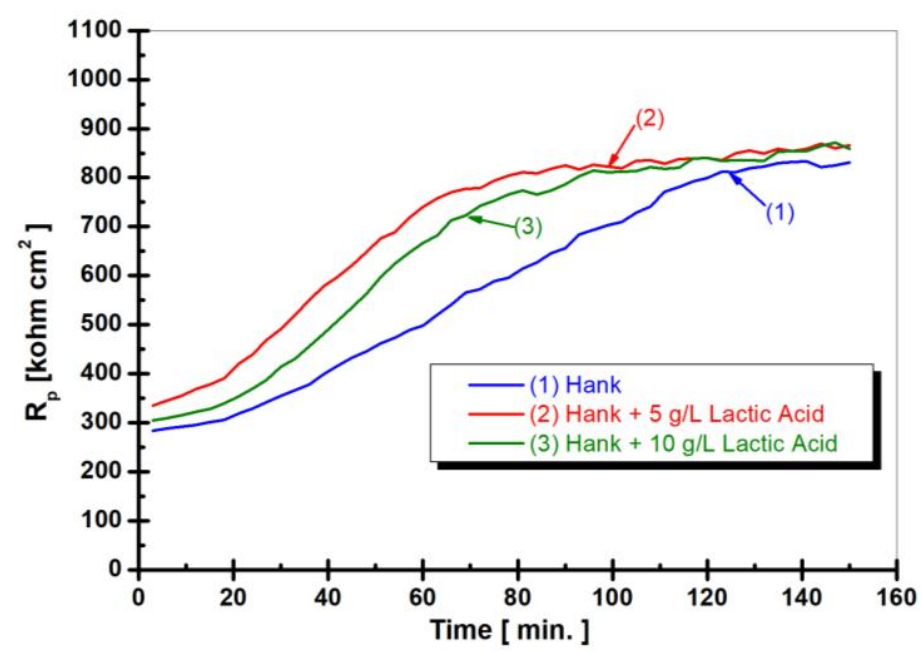

Fig. 7. Evolution of polarization resistance of titanium alloy measured after $48 \mathrm{~h}$ from immersion in: (1) Hank solution; (2) Hank with 5 g/L Lactic Acid added; (3) Hank with $10 \mathrm{~g} / \mathrm{L}$ Lactic acid added

After $48 \mathrm{~h}$ the polarization resistance of titanium alloy immersed in Hank solution, Figure 7, show about the same values as at immersion time (Figure 6) from $275 \mathrm{kohm} \cdot \mathrm{cm}^{2}$ to $780 \mathrm{kohm} \cdot \mathrm{cm}^{2}$, confirming a constant corrosion resistance in time. The polarization resistance of titanium alloy immersed in both Lactic Acid concentration show an increase of polarization resistance from 300 to about $800 \mathrm{kohm} \cdot \mathrm{cm}^{2}$, being close each other.

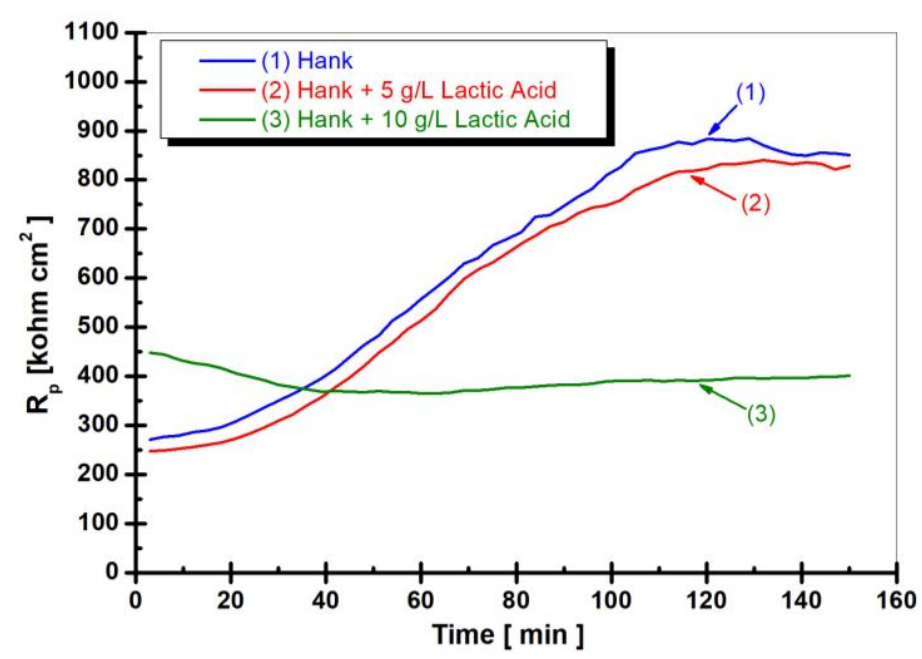

Fig. 8. Evolution of polarization resistance of titanium alloy measured after $168 \mathrm{~h}$ from immersion in: (1) Hank solution; (2) Hank with $5 \mathrm{~g} / \mathrm{L}$ Lactic Acid added; (3) Hank with $10 \mathrm{~g} / \mathrm{L}$ Lactic acid added 
From Figure 8 the polarization resistance of titanium alloy changes dramatically when is immersed in Hank solution with $10 \mathrm{~g} / \mathrm{L}$ Lactic Acid, after 168 from immersion. While, the polarization resistance of titanium alloy immersed in Hank and Hank with $5 \mathrm{~g} / \mathrm{L}$ Lactic Acid preserve the same behaviour by increasing from $275 \mathrm{kohm} \cdot \mathrm{cm}^{2}$ to 800 $\mathrm{kohm} \cdot \mathrm{cm}^{2}$, the polarization resistance of titanium alloy immersed in Hank with $10 \mathrm{~g} / \mathrm{L}$ Lactic Acid shift to lower values from $475 \mathrm{kohm} \cdot \mathrm{cm}^{2}$ to $350 \mathrm{kohm} \cdot \mathrm{cm}^{2}$ preserving the decreasing tendency.

\section{Conclusions}

The corrosion behaviour of the Ti6Al4V in Hank biological solution with addition of two concentration of Lactic Acid monitored at different period from immersion time respectively $0 \mathrm{~h}$ (at immersion time), after $48 \mathrm{~h}$ from immersion time and after $168 \mathrm{~h}$ from immersion time was studied in this research work by electrochemical methods.

From the electrochemical methods used for this study, the following conclusions can be drawn:

- From monitoring of the open circuit potential measurement at different periods of immersion time, it is observed that the addition of Lactic Acid in the concentration of $5 \mathrm{~g} / \mathrm{L}$ and $10 \mathrm{~g} / \mathrm{L}$ in the Hank biological solution leads to a shift of the potential towards more positive values as compared to the biological solution without addition of lactic acid. It can be concluded that the effect of Lactic Acid is changing during immersion time and therefore will contribute to progression of corrosion process on titanium alloy surface immersed in Hank solution.

- From the evolution of the polarization resistance at time 0 , it is observed that the addition of $10 \mathrm{~g} / \mathrm{L}$ lactic acid in the Hank biological solution leads to an increase in the value of the polarization resistance compared to the biological solution without the addition of Lactic Acid, and in the case of the addition of $5 \mathrm{~g} / \mathrm{L}$ Lactic Acid in solution can be observed a decrease in polarization resistance compared to the solution containing $10 \mathrm{~g} / \mathrm{L}$ lactic acid and Hank biological solution. A high polarization resistance value means a low corrosion rate and a low value of the polarization resistance means a high corrosion rate.

- After 48 hours from immersion time it is observed that a change takes place: In this case of the addition of Lactic Acid at a concentration of $5 \mathrm{~g} / \mathrm{L}$ in Hank biological solution the polarization resistance has the highest value, while that with $10 \mathrm{~g} / \mathrm{L}$ Lactic Acid decreases in comparison with Hank without Lactic Acid, and the polarization resistance of Ti6Al4V immersed in the Hank solution remains approximately constant.
- From the polarization resistance of Ti6Al4V alloy immersed in three solution after 168 hours from immersion time it can be observed that the value of polarization resistance decreases gradually with addition of Lactic Acid in Hank biological solution.

As an overall conclusion from this study is that the presence of Lactic Acid, one of metabolic product of microorganisms could destabilizes the interface of titanium alloy implant material with biological solution affecting its corrosion resistance by improving the corrosion rate (decreasing the polarization resistance).

\section{References}

[1]. Benea L., Coroziune şi Protecţii Anticorozive - De la Teorie la Practică, Editura Academica, ISBN: 978-973-8937-99-4, 2017.

[2]. Benea L., Metode avansate de investigare a materialelor, Editura Academica, ISBN 978-606-606-003-5, 2017.

[3]. Simionescu N., Benea L., Dumitrascu V. M., The Synergistic effect of proteins and reactive oxygen species on electrochemical behaviour of $316 \mathrm{~L}$ stainless steel for biomedical applications, IOP Conf. Ser.: Mater. Sci. Eng. 374 012058, 2018.

[4]. Ravoiu A., Simionescu N., Benea L., Influence of different concentration of hydrogen peroxide on the corrosion behavior of Ti-6Al-4V alloy immersed in physiological solution, IOP Conf. Ser.: Mater. Sci. Eng. 572 012006, 2019

[5]. Kurz W., Mercier J. P., Zambelli G., Traite des Matériaux. 1. Introduction à la Science des Matériaux, Deuxième Edition, Presses Polytechniques et Universitaires Romandes, Suisse, ISBN: 2-88074-216-1, 1995.

[6]. Thevenot P., Hu W., Tang L., Surface chemistry influences implant biocompatibility, Curr. Top Med. Chem. 8(4) 270, 2008.

[7]. De Avila E., de Molon R., Palomari Spolidorio D., de Assis Mollo Jr. F., Implications of surface and bulk properties of abutment implants and their degradation in the health of periodontal tissue, Materials. 6(12), 5951, 2013.

[8]. Olmedo D. G., Tasat D. R., Duffo G., Guglielmotti M. B., Cabrini R. L., The issue of corrosion in dental implants: A review, Acta Odontol, Latinoam, 22, p. 3-9, 2009.

[9]. Rodrigues D. C., Valderrama P., Wilson T. G., Palmer Jr. K., Thomas A., Sridhar S., Adapalli A., Burbano M., Wadhwani C., Titanium Corrosion Mechanisms in the Oral Environment: A Retrieval Study, Materials, 6, 5258, 2013.

[10]. Eliaz N., Corrosion of metallic biomaterials: A review, Materials, 12(3) 407, 2019.

[11]. Benea L., Mardare Dănăilă E., Bounegru I., Challenges in corrosion protection using vegetable extracts as inhibitors Electrochemical studies, The Annals of "Dunarea de Jos" University of Galati, Fascicle IX, Metallurgy and Materials Science, No. 3, 2014.

[12]. Benea L., Dănăilă E., Dumitraşcu V. M., Vegetable extracts as inhibitors of carbon steel corrosion in acidic environment, Advanced Materials Research, 1139, 46, 2016.

[13]. Qu Q., Wang L., Chen Y., Li L., He Y., Ding Z., Corrosion behavior of titanium in artificial saliva by lactic acid, Materials, 7(8), 5528, 2014.

[14]. Banu A., Marcu M., Juganaru C., Osiceanu P., Anastasescu M., Capra L., Corrosion behavior of CoCrMoW cast alloy in lactic acid environment for surgical applications, Arab. J. Chem., 12(8), 2007, 2017.

[15]. Takahashi M., Kikuchi M., Takada Y., Corrosion behavior of Ti-Ag alloys used in dentistry in lactic acid solution, Met. Mater, Int. 17(1), 175, 2011.

[16]. Perez N., Electrochemistry and corrosion science, Kluwer Academic Publishers, Boston, 83, 2004. 